\title{
CHEMICAL CAUTERIZATION BY USING TRICHLOROACETIC ACID IN TYMPANIC MEMBRANE PERFORATIONS: OUR EXPERIENCE
}

\author{
Ganesh Bala1, Kannappan A. L2, Nahas T. K33, Arun Khosh ${ }^{4}$
}

${ }^{1}$ Assistant Professor, Department of ENT, Vinayaka Missions Medical College and Hospital.

${ }^{2}$ Post Graduate, Department of ENT, Vinayaka Missions Medical College and Hospital.

${ }^{3}$ Post Graduate, Department of ENT, Vinayaka Missions Medical College and Hospital.

${ }_{4}^{4}$ Post Graduate, Department of ENT, Vinayaka Missions Medical College and Hospital.

\begin{tabular}{l}
\hline ABSTRACT \\
\hline OBJECTIVE \\
In developing countries like India, where tertiary medical facility is not available to all people, treatment should be easily feasible. \\
Small and cost effective procedures like Chemical Cauterization may be a good option for restoring the continuity of tympanic \\
membrane in patients with non-healing perforation in the pars tensa.
\end{tabular}

AIM

To study the effectiveness of chemical cauterisation using trichloroacetic acid in chronic non-healing small dry perforation.

\section{MATERIALS AND METHODS}

40 patients with non-healing dry tympanic membrane perforations were included in the study; 30 percentage TCA was used to cauterize the margins of the perforation. The study was conducted in ENT Department of Vinayaka Missions Medical College and Hospital for duration of 1 year from June 2014 to June 2015.

\section{RESULTS}

The success rate of the procedure is $92.5 \%$.

\section{CONCLUSION}

It is a promising office-based technique for closure of chronic small dry tympanic membrane perforations. It is a relatively easy, simple, safe and economical procedure.

\section{KEYWORDS}

Chemical Cauterization, Hearing Results, Tympanic Membrane Perforations.

HOW TO CITE THIS ARTICLE: Bala G, Kannappan AL, Nahas TK, et al. Chemical cauterization by using trichloroacetic acid in tympanic membrane perforations: our experience. J. Evolution Med. Dent. Sci. 2016;5(34):1903-1905,

DOI: $10.14260 /$ jemds/2016/450

\section{INTRODUCTION}

Major otolaryngological problem faced in India are discharging ear and deafness. The commonest disease seen in otolaryngologic clinics is probably CSOM. Chronic otitis media was found to be a major cause of conductive hearing impairment. It is one of the commonest cause for hearing loss that mainly result due to tympanic membrane perforations.(1) It is important for early diagnosis of chronic otitis media in order to prevent its long-term effects, especially hearing impairment. A history of previous ear discharge, especially when accompanied by episodes of cold, sore throat, cough or some other symptom of upper respiratory infection, should raise the suspicion of CSOM.(2) Without any interventions, almost $80 \%$ of tympanic membrane perforations of any size heal, the rest become chronic and require surgery. Typically, these non-healing perforations require tympanoplasty for closure.(3) Medical costs associated with tympanoplasty have recently compelled investigators to search for less expensive, simple non-surgical methods. (4)

Financial or Other, Competing Interest: None.

Submission 10-03-2016, Peer Review 07-04-2016,

Acceptance 12-04-2016, Published 27-04-2016.

Corresponding Author:

Dr. Ganesh Bala,

Assistant Professor,

Department of ENT,

Vinayaka Missions Medical College and Hospital.

E-mail: gbala.mbbs@gmail.com

DOI: $10.14260 /$ jemds $/ 2016 / 450$
Without closure of perforation, morbidity may include chronic otorrhoea and cholesteatoma formation, deterioration of hearing.(5) The purposes of closing chronic dry perforations of the tympanic membrane are to improve hearing and prevent middle ear infections.(6) Closure isolates the middle ear from external environment and prevent contamination by exposure to pathogens and restores the vibratory area of the membrane and affords round window protection.(7) Aetiologically, tympanic membrane perforations are either due to inflammation or trauma.(1)

Unless there is a coexisting eustachian tube dysfunction, which is the main reason for a permanent perforation, most of the perforations due to otitis media heal.(8) Traumatic perforations usually heal spontaneously and it is preferable to wait for at least 3 weeks prior to any intervention.(6) $\mathrm{A}$ perforated tympanic membrane results in loss of hearing due to decreased drum area and liability to recurrent infection of the middle ear mucosa. (9) These problems limit the patient's participation in water sports and for job recruitment in the military service and as a motor vehicle driver.(10)

\section{MATERIALS AND METHODS}

1. This is a prospective study performed in the Department of ENT Vinayaka Missions Medical College, Karaikal.

2. Study Period: Patients attending the ENT OPD of Vinayaka Missions Medical College Hospital during the period from June 2014 to June 2015.

3. Sample Size: Total 40 patients. 


\section{Inclusive Criteria}

1. Chronic Non-Discharging Ears.

2. Dry Central Perforation for Minimum 6 Weeks.

3. Involving any one of the Quadrants.

4. Mild Conductive Hearing Loss $(<40 \mathrm{db})$.

5. Normal Eustachian Tube and Cochlear Function.

\section{Exclusion Criteria}

1. Small Perforation with Discharge.

2. Moderate Hearing Loss $(>40 \mathrm{db}$ )

3. Large Central Perforation.

4. Atticoantral type of CSOM.

Hearing was assessed by tuning fork tests and pure tone audiometry. The technique was carried out as an OPD procedure. For those who had bilateral perforations, one ear was treated first and the other ear was treated 6 weeks to 3 months later. For the initial application, 4\% Xylocaine was used to anaesthetize the tympanic membrane by adding a few drops into a small cotton ball and placing it into the external canal wall over the surface of the tympanic membrane for about $10 \mathrm{~min}$. Under the microscope, the rim of the perforation was cauterized using a cotton tipped applicator dipped in $50 \%$ trichloroacetic acid until a white cauterized margin $0.5 \mathrm{~mm}$ in width is created. Care was taken not to damage the adjacent structures.

Once the blanching of the rim was completed, a sterile cotton piece which was moistened with antibiotic drop was placed over the perforation. Repetition of the cautery at weekly intervals is done, many of them requiring more than one application and the technique was repeated for a maximum of six times. After the first application, an antibiotic was given for 1 week and Neosporin with hydrocortisone ear drops were instilled for 3 weeks.

During followup, an otoscopic examination and an otoendoscopy will be performed to assess perforation size and improvement in hearing.

\section{RESULTS}

Total 40 patients were treated. The study included unilateral central perforation of the tympanic membrane in 36 cases, post myringoplasty residual and recurrent perforation in 4 cases due to coryza in the same patients. Successful closure of the central perforation was noted in average 4 applications. A maximum of six applications were done before healing was noticed in two patients and a minimum of one application done in one patient. Out of 40 perforations, 37 healed, 3 did not heal and underwent for myringoplasty later. This clinical study showing application of trichloroacetic acid for treatment of small sized central perforation of tympanic membrane $(3 \mathrm{~mm})$ and proves to have a beneficial effect in healing in selected patients. The smaller perforations requiring fewer number of applications. An overall success rate of $92.5 \%$ was achieved in this study.

\section{DISCUSSION}

The Tympanic Membrane (TM) plays a significant role in the physiology of hearing. It is very important in the pathophysiology of chronic inflammatory middle ear diseases. The tympanic membrane perforations significantly impair the quality of life in patients.(1) A simple perforation of the tympanic membrane with no additional lesion of the middle ear transformer mechanism has two different effects on the hearing.

First, there is the diminished surface area of tympanic membrane on which sound pressure is exerted, resulting in dampened ossicular chain excursion. For a small $(1 \mathrm{~mm})$ perforation, Békésy found that the effect on ossicular motion is confined to sounds below $400 \mathrm{~Hz}$ and is $12 \mathrm{~dB}$ at $100 \mathrm{~Hz}, 29$ $\mathrm{dB}$ at $50 \mathrm{~Hz}$ and $48 \mathrm{~dB}$ at $10 \mathrm{~Hz}$.(5) A tympanic membrane perforation causes conductive hearing loss due to loss of ossicular coupling, which is again due to loss of sound pressure difference across the tympanic membrane, which provides the primary drive to the motion of the drum and ossicles. In addition, perforation causes a loss that depends on frequency, perforation size and middle ear space.

Perforation induced losses are greatest at lowest frequencies. The volume of middle ear space also affects hearing. Smaller volume results in larger air-bone gap. Different patching materials have also been used. Wright (1956) used cotton patch with neomycin ear drops, while Mitchell (1958) used sterispon gelatin sponge soaked in patient's own blood. Juers reported an $88 \%$ success with an average of 3.7 applications. He had further everted the margins of the perforation under the operating microscope, whereas Derlacki who reported $75 \%$ success in office treatment at biweekly intervals had used cautery alone. Dunlop had a 100\% success with 3-33 treatment at biweekly intervals.(11) T. Santhi reported $73.75 \%$ success rate.(12) In this study, we noted highest success among patients with traumatic perforations. Present study gave an overall success rate of $92 \%$, which is comparable with the previous studies documented in the literature.

\section{CONCLUSION}

It is a promising office-based technique for closure of chronic small dry tympanic membrane perforations. It is a relatively easy, simple, safe and economical procedure. Surgical complications of middle ear surgery can be avoided by this technique. It can be safely tried in those with systemic medical conditions and in whom surgical intervention is contraindicated.

\begin{tabular}{|c|c|}
\hline Age (In Years) & Number of Patients \\
\hline $16-20$ & 5 \\
\hline $21-30$ & 12 \\
\hline $31-40$ & 17 \\
\hline$>40 \quad$ Table 1: Age Group \\
\hline \multicolumn{2}{|c|}{} \\
\hline
\end{tabular}

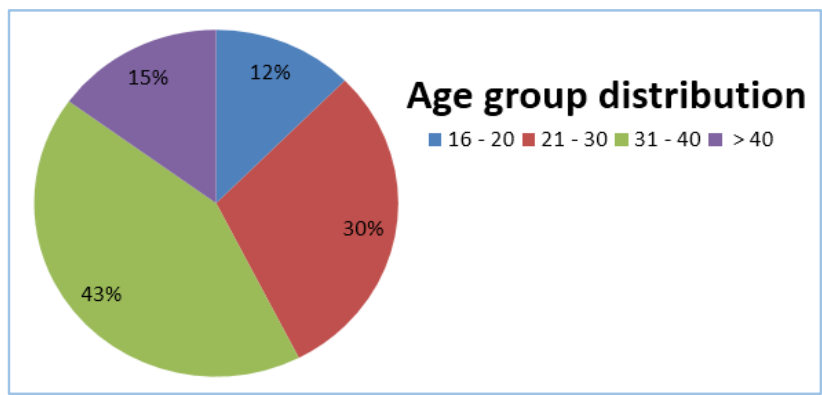

Fig. 1: Age Distribution

\begin{tabular}{|c|c|}
\hline Central Perforation & 36 \\
\hline Post-Myringoplasty (Residual \& Recurrent) & 4 \\
\hline \multicolumn{2}{|c|}{ Table 2: Case Selection } \\
\hline
\end{tabular}




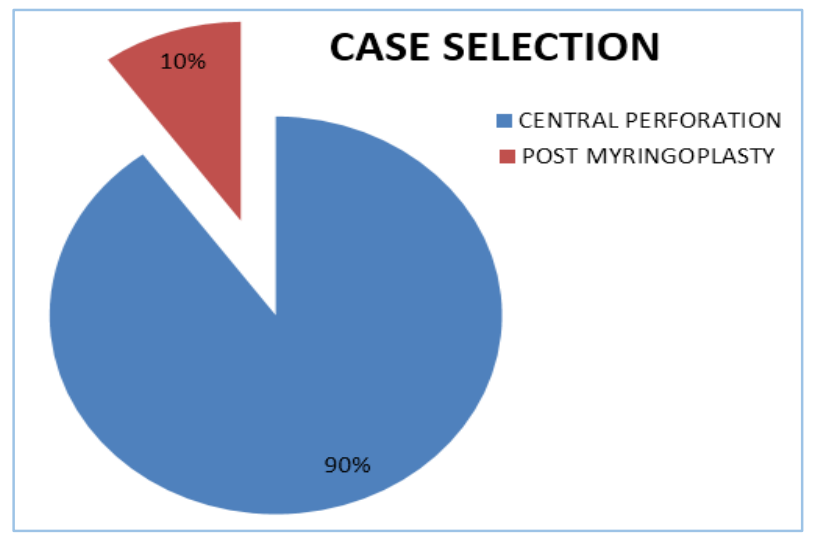

Fig. 2: Case Selection

\begin{tabular}{|c|c|}
\hline Perforation Site & Number of Patients \\
\hline AI & 21 \\
\hline AS & 5 \\
\hline PI & 12 \\
\hline PS & 2 \\
\hline \multicolumn{2}{|c|}{ Table 3: Site of Perforation } \\
\hline
\end{tabular}

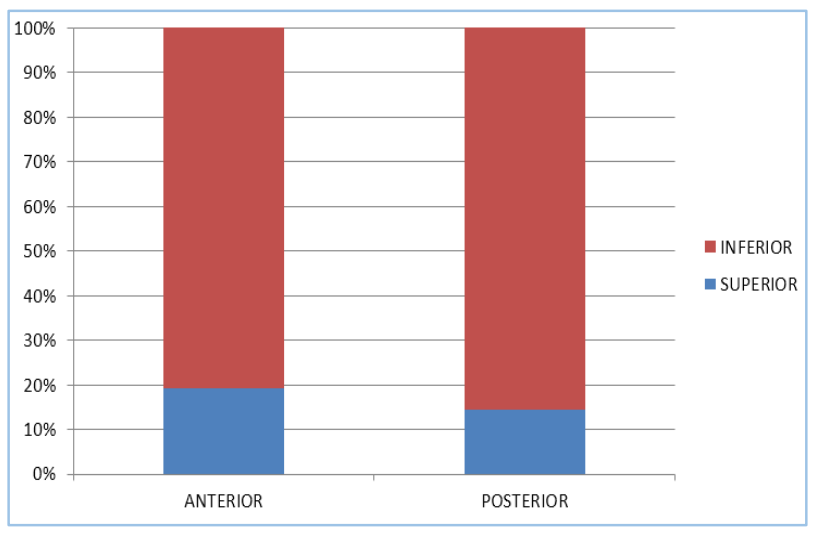

Fig. 3: Site of Perforation

\begin{tabular}{|c|c|}
\hline MINIMAL & 5 \\
\hline MILD & 35 \\
\hline \multicolumn{2}{|c|}{ Table 4: Hearing Loss } \\
\hline
\end{tabular}

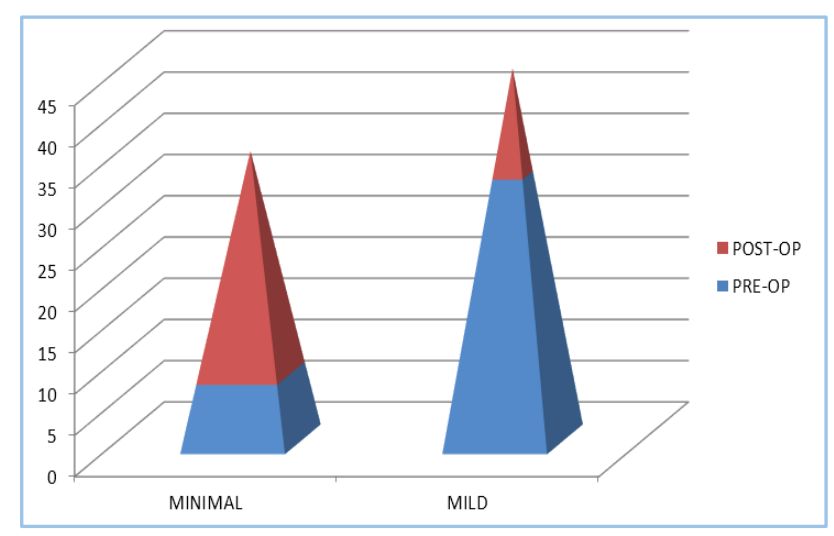

Fig. 4: Hearing Loss (Pre-operative and Post-operative Comparison)

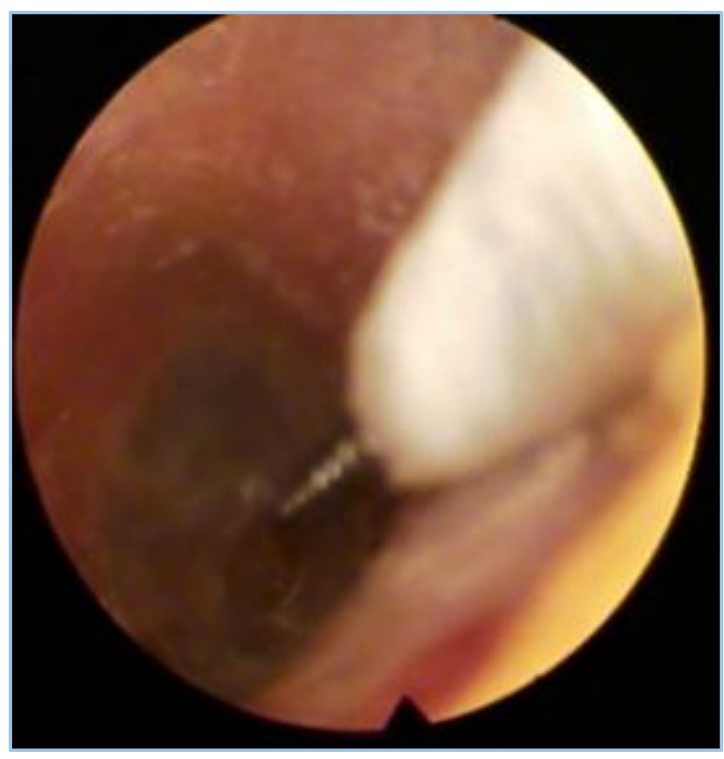

Fig. 5: Technique of TCA Cauterisation

\section{REFERENCES}

1. Aina J Gulya, Lloyd B Minor, Dennnis Poe. GlasscockShambaugh. Surgery of the ear. People's medical publishing house-USA Shelton, Connecticut, 2010;6 $6^{\text {th }}$ edn.

2. Glasscock-Shambaugh. Surgery of the ear. People's medical publishing house-USA Shelton, Connecticut, 2003; $5^{\text {th }}$ edn.

3. Anisur, Rahman. Healing of tympanic membrane perforation: an experimental study. Karolinska Institute and University Hospital Stockhole Sweden ISBN:978-917357-2439, 2007.

4. Kumar N, Madkikar NN, Kishve S, et al. Using middle ear risk index and ET function as parameter for predicting outcome of tympanoplasty. Indian J Otolaryngol Head Neck Surg 2012;64(1):13-6.

5. Banzer M. Disputatio de auditione laesa (Disertation on deafness). 1640.

6. Rupa V, Jacoba A, Joseph A, et al. CSOM: prevalence and practices among rural South Indian children. Int J Pediatr Otorhinol 1999;48(3):217-21.

7. Griffin WL. A retrospective study of traumatic tympanic membrane perforations in a clinical practice. Laryngoscope 1979;89(2 pt 1):261-82.

8. Shyamala R, Reddy PS. The study of bacteriological agents of chronic suppurative otitis media-aerobic culture and evaluation. J Microbiol Biotech Res 2012;2(1):152-62.

9. Browning GG, Gatehouse $\mathrm{S}$. The prevalence of middle ear disease in the adult British population. Clin Otolaryngol Allied Sci 1992;17(4):317-21.

10. Verma AK, Amit Vohra, Anirban Maitra, et al. Epidemiology of CSOM and deafness in a rural area and developing an intervention strategy. Indian $\mathrm{J}$ pediatr 1995;62(6):725-9.

11. Goldman NC. Chemical closure of chronic tympanic membrane perforation. ANZ J Surg 2007;77(10):850-1.

12. Santhi T, Rajan KV. A study of closure of tympanic membrane perforations by chemical cauterization. Indian J Otolaryngol Head Neck Surg 2012;64(4):389-92. 